\title{
PH20 Hyaluronidase-expressing Adenovirus VCN-01
}

National Cancer Institute

\section{Source}

National Cancer Institute. PH20 Hyaluronidase-expressing Adenovirus VCN-01. NCI

Thesaurus. Code C113790.

An oncolytic, replication-competent adenovirus encoding the human

glycosylphosphatidylinositol-anchored enzyme $\mathrm{PH} 20$ hyaluronidase with potential antitumor activity. After intratumoral administration, $\mathrm{PH} 20$ hyaluronidase-expressing adenovirus VCN-01 selectively replicates in tumor cells, which may both cause oncolytic virus-induced cell death and induce the infection of adjacent tumor cells. In addition, the virus expresses hyaluronidase, which hydrolyzes and degrades the hyaluronic acid (HA) that coats tumor cells. The degradation of HA may result in a decrease for both the viscosity of the interstitial space and the tumor's interstitial fluid pressure (IFP). This increases viral spread and may result in the inhibition of tumor cell growth. In addition, HA deg radation facilitates the penetration of chemotherapeutic agents into the tumor. HA is a glycosaminoglycan found in the extracellular matrix (ECM) and is frequently overproduced by various tumor cell types. The presence of HA in tumors correlates with increases in tumor cell growth, metastatic potential, tumor progression and resistance to chemotherapeutic agents. 